\title{
ВЫРАЖЕНИЕ ТЕМПОРАЛЬНОГО ДЕЙКСИСА В РУССКОМ И КИТАЙСКОМ ЯЗЫКАХ
}

\section{EXPRESSION OF TEMPORAL DEIXIS IN THE RUSSIAN AND CHINESE LANGUAGES \\ Qu Rui}

Summary: The article is devoted to studying expression of temporal deixis in the Russian and Chinese languages. The research aims to identifying peculiarities of expressing temporal deixis in the languages under study. Scientific originality of the study lies in dividing the expression of temporal deixis into direct and indirect. As a result of the study, the linguistic means of expressing temporal deixis were established and systematized, and the differences in the expression of temporal deixis in the Russian and Chinese languages were determined.

Keywords: Russian language, Chinese language, temporal deixis, direct expression, indirect expression, linguistic means.

\author{
Цюй Жуй \\ Аспирант, Пекинский университет иностранных языков, \\ (2. Пекин, КНР) \\ qurui@yandex.ru
}

Аннотация: Статья посвящена исследованию выражения темпорального дейксиса в русском и китайском языках. Цель исследования заключается в выявлении особенностей выражения темпорального дейксиса в двух языках. Научная новизна исследования обнаруживается в разделении выражения темпорального дейксиса на непосредственное и косвенное. В результате исследования были установлены и систематизированы языковые средства выражения темпорального дейксиса, определены различия выражения темпорального дейксиса в двух языках.

Ключевые слова: русский язык, китайский язык, темпоральный дейксис, непосредственное выражение, косвенное выражение, языковые средства.

ние темпорального дейксиса недостаточно исследовано и систематизировано.

Для достижения цели исследования поставлена задача установить и классифицировать языковые средства выражения темпорального дейксиса на основе анализа материала русского и китайского языков. В качестве теоретической базы исследования выбраны работы С. Рахимова [4], Хэ Цзыжаня (何自然) и Жань Юнпина (手永平) [8].

Темпоральный дейксис является основным типом дейксиса, указывающим на грамматическое время и временные отношения. Подобно другим дейксисам, темпоральный дейксис характеризуется ситуативностью, эгоцентризмом, субъективностью, мгновенностью и эфемерностью актуального значения [2, с. 5-6]. С. Рахимов отмечает, что выражение дейксиса разделяется на имплицитное и эксплицитное [4, с. 5]. По его мнению, эксплицитное выражение темпорального дейксиса осуществляется морфологическим и лексическим средствами. Что касается имплицитного выражения, то это синтаксическое выражение темпорального дейксиса, в нем важную роль играет предложное сочетание. Мы придерживаемся данного мнения С. Рахимова. Он сознал то, что выражение дейксиса характеризуется иерархичностью.

Во внимание приняли данную характеристику и китайские лингвисты. Опираясь на анализ материала китайского языка, Хэ Цзыжань и Жань Юнпин предлагают понятие «прагматический темпоральный дейксис». Они указывают, что некоторые устойчивые выражения и фра- 
зеологизмы, метафорически выражающие длительность времени и возраст, относятся к темпоральному дейксису, хотя они буквально не имеет связи с выражением значения времени. Например, 不惑 [бу хо] 'без колебаний' обозначает 40 лет. На наш взгляд, данные средства должны быть рассмотрены как средства имплицитного или косвенного выражения темпорального дейксиса.

С учетом иерархичности выражения темпорального дейксиса и особенностей употребления русского и китайского языков мы разделяем выражение темпорального дейксиса на непосредственное и косвенное.

\section{1. Непосредственное выражение темпорального мейксиса}

Цель употребления темпорального дейксиса заключается в осуществлении выражения грамматического времени и временных отношений. В русском и китайском языках грамматическое время соответственно понимается как темпоральность и фактор времени. Темпоральность отражает «восприятие и осмысление человеком времени обозначаемых ситуаций и их элементов по отношению к моменту речи говорящего или иной точке отсчета» $[1$, с. 5]. Она обнаруживается в временных формах глаголов, употребляемых для выражения настоящего, прошедшего и будущего времени.

1) Однажды он готовил концерт Брамса в Мюнхене (Спивакова С. Не все. 2002. НКРЯ) [3] (прошедшее время).

2) Иванов сидит за столом и читает книгу (Катаев В. Б. Чехов плюс... Предшественники, современники, преемники. 2004. НКРЯ) [Там же] (настоящее время).

3) Он npuedem во вторник (Токарева В. Своя правда // «Новый Мир». 2002. НКРЯ) [Там же] (будущее время).

Фактор времени понимается как время действия и относительное положение действия от момента речи или иного момента на временной оси [6, с. 417]. Он отражается временными вспомогательными словами (着 [чжэ] 'быть в процессе какого-либо действия', 了 [лэ], 过 [го] 'близки по значению к суффиксам глаголов в прошедшем времени'), временными существительными ( 未来 [вэй лай] 'будущее', 今天 [цзинь тянь] 'сегодняшний день') и временными наречиями (正在 [чжэн цзай] 'находиться в стадии осуществления', 刚才 [ган цай] 'только что') [9, с. 300-326]. Например:

1）古典音乐正在被更多的人接受。(人民日报. 人民日 报出版社, 1987.10.06 ‘Газета Жэньминьжибо. Изд-во «Газета Жэньминьжибо». 06.10.1987') [7] (настоящее время). /

[гу дянь инь юе чжэн изай бэй гэн до дэ жэнь цзе шоу]

'Классическую музыку принимают все больше людей' (здесь и далее перевод автора статьи. - Ц. Ж.).

2) 王惠莹从小就爱上了体操。(天津日报. 天津日报社， 1987.11.27 'Тэньцзинь Дейли. Изд-во «Тэньцзинь Дейли». 27.11.1987') [Там же] (прошедшее время). / [ван хуэй ин цун сяо цзю ай шан лэ ти иао]

'С детства Ван Хуэйин влюбился в гимнастику'.

3) 一场大雨即将来临。(河北日报.河北日报社， 1991.10.26 'Хэбэйский ежедневник. Изд-во «Хэбэйский ежедневник». 26.10.1991') [Там же] (будущее время). /

[и чан да юй цзи цзян лай линь]

'Надвигается сильный дождь'.

В русском и китайском языках, выражение временных отношений преимущественно осуществляется с помощью временных наречий, выражающих точку времени, отрезок времени, частотность и порядок времени. Среди них дейктическую функцию выполняют временные указательные наречия, которые употребляются и понимаются в зависимости от конкретной конситуации речи. Например, недавно, днем, часто, 夜里 [е ли] 'ночью', 有时 [ю ши] 'иногда', 然后 [жань хоу] 'потом'. Они отличаются от слов, выражающих номинативное время (понедельник, 2020 год, 星期五 [син ци у] 'пятница'), семантика которых независима и абсолютна. В языке выражение значения времени разделяется на дейктическое и недейктическое. Основой недейктического выражения является номинативное время, при его употреблении и понимании точкой отсчета не является момент речи говорящего [8, с. 35].

Опираясь на наблюдение за индоевропейскими языками, С. Рахимов отмечает, что предлог является важным и особым языковым средством при осуществлении временной либо пространственной координации объектов внешней действительности. А.А. Закарян указывает, что при осуществлении пространственной ориентации объектов предлоги способны обозначать статическую или динамическую локализацию объектов. По мнению Рахимова, данная классификация тоже подходит предлогам, употребляемые для выражения временной локализации объектов. Временные предлоги, выполняющие функцию статистической локализации, соотносят действие с определенным моментом на временной шкале (в 2 часа) или со временем совершения другого действия (перед обедом). Временные предлоги, употребляемые для реализации динамической локальности, соотносят действие с периодом времени (до его возвращения). В китайском языке существуют аналогичные средства выражения, например: 在八点[цзай ба дянь]'в 8 часов', 从 那天起 [цун на тянь ци] 'с того дня'.

Надо подчеркнуть, что вышеуказанное предложное сочетание, выражающее временное значения должно быть разделено на сочетание предлога со словами, имеющими временную семантику, т.е. временными словами и сочетание предлога со словами, обладающими временным атрибутом. Безусловно, что сами слова, обозначающие момент и период времени могут быть рассмотрены как собственное время, а слова, выражающие значение действия не относятся к временным словам. 
Последние слова обладают не временной семантикой, а временным атрибутом. Временная семантика и временный атрибут различаются. Слова со временной семантикой могут самостоятельно выражать значение времени, а слова со временным атрибутом не могут. Мы считаем, что сочетание предлога со временными словами относится к средствам непосредственного выражения темпорального дейксиса, другой вид сочетания - средствам косвенного выражения темпорального дейксиса. О косвенном выражении мы будем рассуждать во второй части статьи.

Одним словом, что к средствам непосредственного выражения темпорального дейксиса относятся временные формы глаголов (русский язык: спряжение глаголов; китайский язык: сочетание глаголов со служебными словами), временные указательные наречия, сочетание предлога со временными словами.

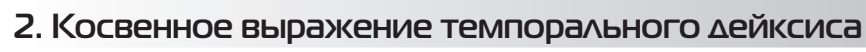

Не подлежит сомнению, что помимо непосредственного выражения темпорального дейксиса существует и косвенное выражение. В русском и китайском языках косвенное выражение темпорального дейксиса в первую очередь осуществляется посредством производных временных слов, которые состоят из слов со временным атрибутом и маркировок.

Мы отметили, что временной атрибут и временная семантика различаются. Под временным атрибутом понимается как темпоральные семантические характеристики, существующие имплицитно в семантическом компоненте языковой единицы. Он рассматривается как потенциальную семантику языковой единицы. Например, «окончание университета» представляет собой не время, а событие. Но это событие обладает временной соотнесенностью, т.е. оно происходит в определенное время. Именно данная характеристика считается временным атрибутом данного словосочетания.

Временной атрибут может превращаться в заметную временную семантику с помощью маркировочных средств. Например, до окончания университета, noсле окончания университета. Данные выражения принадлежат к темпоральным дейксисам. Маркировочные средства аналогичны вспомогательным словам, только в сочетании со словами со временными атрибутами могут быть рассмотрены как темпоральный дейксис и выражают полное временное значение. В русском языке к маркировочным средствам относятся существительные, предлоги и наречия, а в китайском языке - существительные, предлоги и союзы. Вообще говоря, маркировочные средства разделяются на следующие виды:

1) маркировка наименования: эпоха феодализма, Бронзовый век, 学生时期 [сюе шэн ши ци] 'школьные годы', 石器时代[ши ци ши дай] 'каменный век';

2) маркировка временной ориентации: перед револючией, за обедом, 大学毕业后 [да сюе би е хоу] 'после окончания университета', 晚饭前[вань фань цянь] 'перед ужином';

3) маркировка начала, конца и течения времени: с Отечественной войны, до его возвращения, 自从上次见 到你 [цзы цун шан цы цзянь дао ни]'с последней встречи с вами';

Кроме вышеуказанного, косвенное выражение темпорального дейксиса может быть осуществлено при употреблении выражений, связанных с понятием движения, что объясняется тем, что суть течения времени понимается как вечное движение. Движение, обладающее временной ориентированностью, включает в себя астрономическое, фенологическое и человеческое.

Астрономическое движение отражает смену времени дня и времен года. Оно разделяется на движение планет и метеорологическое явление.

1) Ну, Лизок, луна восходит и нам время в парк (Андреев Л.Н. Екатерина Ивановна. Пьеса в четырех действиях. 1912) [3] (луна восходит - символ вечера).

2) На уличе очень холодно и неприятно: второй день метет метель (Рязанова И. Отит // «Здоровье». 1999.03.15. НКРЯ) [Там же] (метель - символ зимы).

3) 每天刚露鱼肚日，老主顾们就站在门外等着开业(人 民日报. 人民日报出版社, 1996.03.28 ‘Газета Жэньминьжибо. Изд-во «Газета Жэньминьжибо». 28.03.1996') [5] (鱼肚白[юй ду бай] 'предрассветный цвет неба' - символ рассвета). /

[мэй тянь ган лу юй ду бай, лао чжу гу мэнь цзю чжань цзай мэнь вай дэн чжэ кай е]

'Каждый день на рассвете старые клиенты стоят у дверей в ожидании открытия'.

4) 尽管朔风燷洌，市场里顾客仍然络绎不绝。(人民日 报. 人民日报出版社，1960.01.28 ‘Газета Жэньминьжибо. Изд-во «Газета Жэньминьжибо». 28.01.1960') [7] (朔风 [шо фэн] 'северный ветер' - символы зимнего сезона). /

[цзинь гуань шо фэн линь ле, ши чан ли гу кэ жэн жань ло и бу цзюе]

'Несмотря на сильный северный ветер, на рынке попрежнему нескончаемый поток покупателей.'

С астрономическим движением тесно связывается фенологическое движение, имеющее в виду регулярные сезонные явления природы. Данными движениями отражается смена времен года.

Давно стаял снег, вокруг совсем тепло (Членов А.Ф. Как Алешка жил на Севере. 1978) [3].

В этом предложении выражение «стаял снег» символизирует наступление весны. 
Функцию временной ориентации выполняют выражения о личных жизненных привычках, графике работы, стиле одежды, праздничных обычаях народа и развлекательных деятельностях. Например:

1) Шуба Ольги на месте, и санки наши стоят, значит, здесь (Букша К. ана. 2002) [3].

2）他正坐在树荫下和几位朋友乘凉、聊天。(人民日 报. 人民日报出版社, 2017.06.22 ‘Газета Жэньминьжибо. Изд-во «Газета Жэньминьжибо». 22.06.2017') [5]. /

[mа чжэн цзо цзай шу инь ся хэ цзи вэй пэн ю чэн лян ляо тянь]

'Сидя в тени под деревом, они с несколькими друзьями наслаждаются прохладой и разговаривают!'

В примерах слова «шуба» и «санки» символизирует зиму, а действия «сидеть в тени под деревом» и «наслаждаться прохладой» - лето, чем определен временной фон описательных сцен.

Таким образом, для осуществления косвенного выражения темпорального дейксиса могут быть употребляемы такие средства, как производные временные слова, состоящие из слов с временным атрибутом и маркиро- вок, а также слова, косвенно или имплицитно выражающие значение времени.

Опираясь на установленные и классифицированные языковые средства выражения темпорального дейксис в русском и китайском языках, мы пришли к следующим выводам.

1) Выражение темпорального дейксиса разделяется на непосредственное и косвенное, что соответствует иерархичности выражения дейксиса.

2) При непосредственном выражении темпорального дейксиса в русском языке имеются более богатые языковые средства, охватывающие морфологический и лексический уровни, а в китайском языке темпоральный дейксис выражается лексическими средствами.

3) Как в русском, так и в китайском языке косвенное выражение темпорального дейксиса осуществляется такими универсальными средствами, как производные временные слова и выражения, имплицитно обладающие временной ориентированностью.

\section{ЛИТЕРАТУРА}

1. Бондарко А.В. Функциональная грамматика. Темпоральность. Модальность. Л.: Наука, 1990. 264 с.

2. Кацнельсон С.Д. Содержание слова, значение и обозначение. М.: Едиториал УРСС, 2011. 112с.

3. Национальный корпус русского языка (НКРЯ) [Электронный ресурc]. URL: http://ruscorpora.ru/ (дата обращения: 04.12.2020).

4. Рахимов С. Речевая коммуникация и проблема дейксиса в разносистемных языках.Ташкент: Изд-во «ФАН» УзССР, 1989.90 с.

5. 北京语言大学： ВСС语料库 (Пекинский университет языка и культуры: Корпус китайского языка ВСC) [Электронный pecypc]. URL: http://bcc.blcu.edu. cn/ (дата обращения: 04.12.2020).

6. 陈平. 论现代汉语时间系统的三元结构. 中国语文. 1988. 第6期, 第401-422页 (Чэнь Пин. 0 тройной структуре системы времени в современном китайском языке // Китайский язык. 1988. № 6. С. 401-422).

7. 国家语委现代汉语语料库 (Корпус современного китайского языка Государственного комитета по работе в области языка и письменности) [Электронный ресурc]. URL: http://www.cncorpus.org/ (дата обращения: 25.10.2020).

8. 何自然，永平. 新编语用学概论. 北京: 北京大学出版社. 2010， 379页 (Хэ Цзыжань, Жань Юнпин. Общее введение в прагматику. Пекин: Изд-во Пекинского университета, 2010. 379 с.).

9. 吕叔湘. 中国文法要略. 北京：商务印书馆. 2018，681页 (Люй Шусян. Очерк грамматики китайского языка. Пекин: Изд-во Коммерческое, 2018. 681 c.).

10. 索振羽. 语用学教程. 北京: 北京大学出版社. 2000，223页 (Со Чжэньюй. Учебное пособие по прагматике. Пекин: Изд-во Пекинского университеTa, 2000.223 c.).

11. 俞东明. 什么是语用学. 上海: 上海外语教育出版社. 2011，247页 (Юй Дунмин. Что такое прагматика. Шанхай: Шанхайское изд-во обучения иностранным языкам, 2011. 247 с.). 